\section{Fundamentals of seismic wave propagation}

\section{by Chris Chapman}

Cambridge University Press, July 2004, hardback, £45.00, ISBN 10: 052181538X/ ISBN 13: 9780521815383.

Simply put, this is a great book for professional researchers in seismology. What I mean is, despite the statement in the Preface that 'This book is intended as a text for a graduate or a research level course', I cannot imagine finding a graduate student who can enjoy learning materials from this book. Prerequisite for understanding this book seems to be too hard for graduate students now. I, for one, have not even tried in a lecture for graduate students to explain what the Cagniard method is in the last ten years. This is, of course, not the fault of this book but rather the outcome of our educational system (in the United States), or the values held in today's society. Unfortunately, so few of our graduate students ever learn the beauty and magic in such concepts as contour integration and the meaning of poles in different Riemann sheets. Readers must have some exposure to these concepts before digesting the materials in this book.

In the meantime, the reward of reading through this book for researchers in seismology, including exploration seismology, should be great. The topic is focused on highfrequency seismic wave propagation in the elastic medium, for which the author has been a world-renowned leader in the last thirty years.

Just like his research papers, the whole book is a carefully planned piece of work. It starts out with some sketches of the type of problems the book tries to understand (Chapter 2) which provide basic ideas for the nature of questions that are pursued. Summary of notations and basic formulas, including useful set of mathematical transforms (Chapter 3) and the review of continuum mechanics (Chapter 4) follow. They are reviews of basic concepts but include uncommon features. For example, the discussion on rewriting the stress-strain relation to a valid vector-matrix equation (section 4.4.2) is something I have not seen in other books. I am also fond of the crisp, succinct introduction to the stress gluts, a section on source process in 4.6. It is essentially a fourpage summary of Backus and Mulcahy's two papers in 1976 without distribution theory. And it seems to me that the main physical points Backus and Mulcahy tried to address are here.

Starting in Chapter 5 up to Chapter 9, the book covers all the semi-analytical methods, such as ray theory, the Cagniard method, the WKBJ method, and the Kennett's expansion method. The last chapter, Chapter 10, is a collection of four 'frontier' topics related to

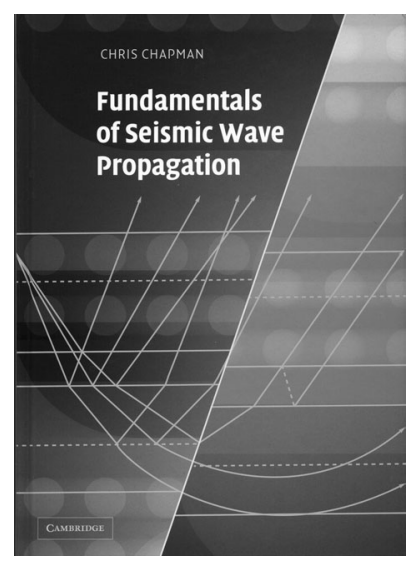

the generalization of ray theory. It includes the Maslov method, the quasi-isotropic ray theory, the Born scattering theory and the Kirchhoff surface integral method.

So, what are the rewards for reading through this book? Certainly it provides the current status of semi-analytical methods on high-frequency seismic wave propagation pointing out their power and problems. However, I have found reading this book an enlightening experience from two other aspects.

First, I felt I gained much from his succinct summary of historical work. The author tries to go back to the original papers on most subjects. And then he provides his summary of those papers in a paragraph or sometimes over a few pages. They are often great summaries of the main points of much more voluminous work. I already mentioned the source theory by Backus and Mulcahy in the above but the Kennett's ray expansion method is another. The author spends only 6 pages to explain the crux of this approach including its strength on numerical stability and the ease of including fluid layers in solids.

The second reward is from his insights (and discussion) on subtle points in theory. For example, he discusses the effects of existence of a thin anisotropic layer for transmission coefficients (section 7.2.4.4) and how the coefficient becomes close to 1 as the layer thickness approaches zero. We tend to regard such a point as obvious and never seeks a more rigorous demonstration. But there could be a concern because many well$\log$ data reveal stacks of thin (anisotropic) layers which may scatter incoming waves at various locations and make transmission coefficient to deviate from 1 . But a simple formula, equation (7.2.87) assures us that the transmission coefficient asymptotically approaches one. Therefore, we do not have to be concerned about such scattering effects for low frequency waves. Such a subtle point is rarely discussed in most seismological textbooks. There are other examples like this in this book and I think we are well rewarded for getting the author's insights.

This book is full of exercise problems after each chapter. Some just ask for verification of formulas in the text but others ask much deeper questions. Often, after stating a problem, a question ends with a statement like 'A useful publication is Gilbert (1967)' or 'This problem was described by Knopoff (1958)'. In other words, these questions were subjects of single research papers! They basically supplement the content of the text, and not really are exercise problems to test whether a reader has understood the main text. With problems marked as 'Further reading', the book directs us to the next step of reading materials which may actually take up our whole life-time.

The research field of seismic wave propagation is clearly moving toward more numerically dominated techniques than those discussed in this book. But I believe it is important to learn semi-analytical techniques in this book and gain intuitive insights into wave propagation process in order to make progress in our understanding of Earth structure. Numerical methods may be great in giving us the correct complete seismograms but do not necessarily tell us which part of seismogram is sensitive to which aspect of earth structure. A brute force inversion with purely numerical approaches is still too dangerous and is probably successful because our Earth model is still not close enough to the structure of the real Earth (especially at higher frequencies); it does not seem obvious to me that iterations of brute force approach will lead us to the right solution at present. In my view, there is still great room for creative use of insights in building Earth structure models. In order to gain such insights, we must learn semi-numerical methods from a book like this.

\section{Toshiro Tanimoto}

Professor of Geophysics

Department of Geological Sciences

University of California

Santa Barbara

California 93106

USA

toshiro@geol.ucsb.edu 


\section{3-D seismic interpretation}

\author{
by M. Bacon R. Simm and \\ T. Redshaw
}

Cambridge University Press, 2003,

222pp., hardback, £66.55, ISBN

0521792037 .

This book is an introduction to the ways that 3-D seismic interpretation methods can be used to improve the understanding of the subsurface, with 34 line diagrams, 3 halftones 3 tables and 100 color figures.

Applied geophysics uses a large number of methods to investigate the subsurface. Because of its ability to produce images down to depths of thousands of meters with a resolution of tens of meters, the seismic method has become by far the most commonly used geophysical method in the oil and gas industry. Since 1980's, the quality of seismic information has been greatly improved by the use of 3-D seismic methods.

3-D seismic data have become the key tool used in the petroleum industry to understand the subsurface. In addition to providing excellent structural images, the dense sampling of a 3-D survey can sometimes make it possible to map reservoir quality and the distribution of oil and gas. However, extracting useful information from seismic images remains the interpreter's craft skill, in which elements of geological and geophysical knowledge are combined in varying proportions.

This book was intended for people beginning to develop interpretation skill, either as part of a University course or at the beginning of a career in the oil and gas industry. The publishers assumed that the reader had some general background knowledge of the seismic methods. The book will be indispensable for geoscientists learning to use 3-D seismic data, particularly graduate students of geophysics and petroleum geology, and new entrants into the oil and gas industry.

The authors of this book are professional geophysicists with many years' experience in the oil industry. They are still actively interpreting 3-D seismic data and are therefore able to summarize the current best practice.

Besides several excellent texts that cover the whole range of theory and practice, such as the book of Exploration Seismology published by Cambridge University Press on 1995 , this book is rather to concentrate on the techniques of interpretation that are special to 3-D seismic analysis, or are greatly improved in usefulness by applying them to 3-D datasets, such as amplitude studies, AVO analysis, inversion and time-lapse seismic analysis. Even so, there is enough explanation of the underlying principles to make the book fairly self-contained.

In particular, this book describes the acquisition and processing of 3-D seismic

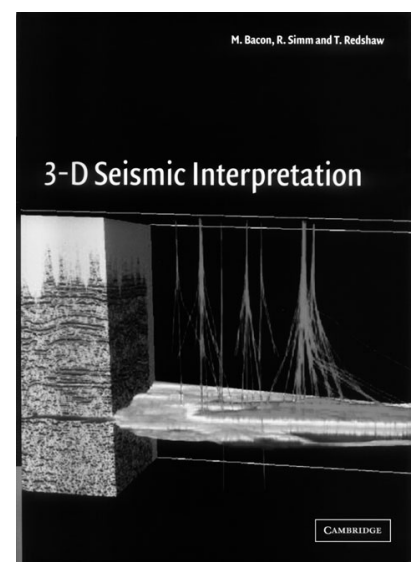

data in some detail, concerning that the interpreters would need to understand the limitations of the seismic data and distinguish misleading artefacts that are likely to exist in the images reaching their desks. Considering that the interpreters sometimes need to interact with specialists in data acquisition and processing, the authors have borrowed some of specialized language from the classic seismic interpretation. Also, any extensive use of mathematics has been avoided in order to make this book easily accepted by potential readers with a diversity of academic background.

The basic framework of this book is constructed with an introduction, 7 main academic chapters and 2 appendixes. References are listed at the end of each chapter and appendix. A number of examples of seismic displays to illustrate the various interpretation techniques are included to give the reader a feeling for the typical quality of modem seismic data.

In the first part of the book, the background of the development of 3-D seismic interpretation is introduced. The topics focus on the seismic data, the migration of seismic data, the data density, the uses of seismic data and the road maps. And it is mentioned at the end of the introduction part of this book that the display polarity should be paid more attention during seismic interpretation.

The $2^{\text {nd }}$ chapter focuses on the 3-D seismic data acquisition and processing methods, including topics of the marine 3-D data acquisition, the marine shear wave acquisition, the 3-D land acquisition, and other types of seismic survey. As for the 3-D data processing methods, the reformat, designature, resampling and gain adjustment, deconvolution, removing multiples, binning, stacking and migration and post-migration processing are specially described.

The $3^{\text {rd }}$ chapter of structural interpretation focuses on the topics of well ties, workstation interpretation and depth conversion; the $4^{\text {th }}$ chapter of geological interpretation focuses on the topics of seismic resolution, seismic stratigraphy, interpretation tools, as well as some examples and faults; the $5^{\text {th }}$ chapter of interpreting seismic amplitudes focuses on the basic rock properties, offset reflectivity, interpreting amplitudes, AVO analysis, and rock physics for seismic modeling; the $6^{\text {th }}$ chapter is named inversion, including the principles, the procedures, the benefits of inversion and the AVO effects; the $7^{\text {th }}$ chapter focuses on 3-D seismic data visualization; and the $8^{\text {th }}$ chapter of timelapse seismic focuses on rock physics, seismic measurements, seismic repeatability, seismic processing, as well as some examples.

At the end of the book, one appendix covers briefly the main issues involved in managing hardware, software and data to create an environment for the interpretation of 3-D seismic data, while the other appendix gives the glossary of the book.

Since the range of topics that might be included is large referring to 3-D seismic interpretation, this book concentrates on those that are of most practical application in the authors' experience. There have been rapid advances in interpretation techniques over the past two decades. In part, this reflects the availability of more computer power at the desktop, so that first-pass interpretations can now often be made in days rather than months. At the same time, data quality has been improving, so that a wealth of detailed subsurface information can be extracted if the right methods are used. The authors have tried to portray the current state of art in both these respects. The combination of the interpreter's ingenuity with even more computer power will surely lead to further developments in the future.

The text is intended as an aid in developing understanding of the techniques of 3-D interpretation. Since the book could not cover all the possible limitations on applicability and accuracy of the methods described, care is needed in applying them in the real world. If the readers were in doubt, the authors suggest that they should seek advice from an experienced geophysicist or geologist.

\section{Dr. $\mathrm{Li} \mathrm{Li}$}

National Earthquake Infrastructure Service China Earthquake Administraion

63, Fuxing Ave.

Beijing 100036

CHINA

Tel: 86-10-88015758

Fax: 86-10-88015793 


\section{The volcano adventure guide}

\section{By Rosaly Lopes}

Cambridge University Press, 2005, 362 pages, hardback, US\$50, ISBN 0521554535 .

Geology is characterized by its closeness to nature, and volcanoes are among the most attractive, enigmatic, and dangerous features on Earth. Volcanoes have formed some of the most beautiful landscapes; they have been associated with ancient myths (the very word Volcano comes from the name of the Roman god of fire, Vulcan), and they have produced many tragic events in human history.

The Volcano Adventure Guide is a hybrid publication between geology and tourism, and quite likely, the first of its kind. Its author, Rosaly Lopes, is a planetary volcanologist working for NASA. This year, she also published Volcanic Worlds: Exploring the Solar System's Volcanoes (Springer Verlag, 2005). With her eyes on the volcanoes of heavenly planets and her feet on many active volcanoes on our own Earth, Lopes has written an informative and charming book. Beautifully illustrated by photos, maps, and figures, the book may even pass as a coffee-table book. It is very useful for people who want to arrange geo-tours to active volcanic sites. Geology teachers and researchers will also find in this book a good package of information about many of the famous, active volcanoes.

The book is divided into two parts. The first part ("Choosing a volcano to visit") is an introduction to the world's volcanoes - their distribution, formation, and types, and how to plan a volcano adventure. Here Lopes presents five survival rules for volcano adventures: (1) stay out of the range of bombs; (2) beware of unstable terrain; (3) plan an escape route; (4) avoid breathing potentially toxic fumes; and (5) watch out for steam and methane explosions

The second part is the meat of the book, offering a guide to and geologic data on several volcanoes in Hawaii (Kilauea, Mauna Loa, and Halekala), in the continental USA (Lassen Peak, Mount St. Helens, Sunset Crater, and Yellowstone), Italy (Vesuvius, the Aeolian islands, Stromboli, Vulcano, and Etna), Greece (Santorini), Iceland (Krafla, Heimaey, and Hekla), Costa Rica (Arenal, Poas, and Irazu), and in the West Indies (Mount Pele and Soufriere Hills).

All of these 20 volcanoes are well known, some better than the others. Kilauea, a classic shield volcano, is the home of the Hawaiian goddess, Pele. Mauna Loa is the world's largest volcanic mountain, towering over $9 \mathrm{~km}$ above the ocean floor and over 4 $\mathrm{km}$ above the sea level! (In this sense, it is even higher than Everest.) Haleakala ("House of the Sun") with $53 \mathrm{~km}$ length and

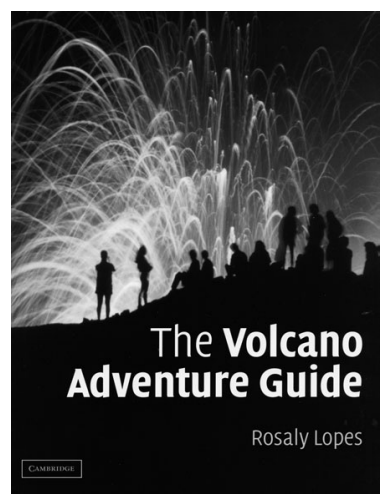

$3 \mathrm{~km}$ height is an impressive volcano on the island of Maui; it last erupted in 1790.

Lassen Peak in the Cascades Range of western USA is the world's largest plug-dome created by a piston-like eruption, eventually plugging its own vent. Mount St. Helens in Washington State made headlines in 1980 , when its explosion killed 57 people, and more recently in 2005 as it erupted again. Sunset Crater in Arizona (named by John Wesley Powell for Arizona's beautiful sunsets) is a national monument and lies en route to Grand Canyon. Yellowstone Plateau is the world's first national park (1872) and one of the most visited tourist attractions in the USA.

Vesuvius, a 1280-m tall stratovolcano in Italy, is infamous for its eruption in 79 A.D. which burnt and buried the towns of Pompeii (with 20,000 people) and Herculaneum (home to 5,000 people) and also killed Pliny the Elder, the first geologist known to die while investigating a volcanic eruption. The Aeolian archipelago, named after the Greek god of the winds, Aeolus, consists of seven volcanic islands carved by erosional processes into a beautiful landscape. Stromboli, "the lighthouse of the Mediterranean," has been continuously active for millennia, and was chosen by Jules Verne as the site for his heroes to embark on their Journey to the Center of the Earth. Vulcano, the southernmost of the Aeolian Islands, has given its name to a host of geologic terms, volcano, volcanology, volcanism, vulcanists, etc. Mount Etna, the largest volcanic mountain in the continental Europe, has fascinated many people, including Sir Charley Lyell who found evidence of Earth's internal dynamism on this mountain.

The Greek volcanic island of Santorini has been occupied for some five thousand years and has both a rich cultural history and superb geologic scenery; its eruption activity during the Pleistocene-Recent has been catalogued into several discrete stages, dating back to 36,000 and 170,000 years ago, respectively. Santorini's most famous eruption, sometime between 1500 and 1550 B.C., is believed to have destroyed the Minoan civilization and given rise to the myth of the Lost Atlantis, first recorded by Plato. The most recent eruption of Santorini took place in 1950.

Moving onto Iceland, Lopes describes the broad volcanic tract of Krafla, the volcanic port town of Heimaey, and Iceland's most famous and active volcano, Hekla, which erupts dangerously every 10 to 30 years. Here also, Lopez highlights the importance of active volcanoes as geothermal resources.

Costa Rica has more than 200 volcanic centers, formed mostly in the last 3 million years. Of these, five have historical records in the past three centuries: Rincon de la Vieja, Arenal, Poas, Irazu, and Turrialba. The first four are located in national parks indicating the role of volcanic mountains in creating the attractive, green landscape of Central America. Rincon de la Vieja ("old woman's corner") is too remote to be visited by many people. Arenal was not recognized as a volcano until it blew up in 1968. Poas, some 19 miles northwest of San Jose, is the most easily visited. Irazu is the highest active volcano $(3,432 \mathrm{~m})$ in Costa Rica. Turrialba ("white tower"), located near a town of the same name, was last erupted in 1866 and is a yet unspoiled region of Costa Rica.

Lopes ends her book with the volcanoes of the West Indies, part of the Lesser Antilles arc in the Caribbean Sea. These subduction-related volcanoes include Mount Pele, whose 1902 eruption killed some 30,000 people of St. Pierre, and Soufriere Hills volcano on the island of Montserrat that have been described in the book.

The author has considered three criteria for selecting the 20 volcanoes in her book. First the volcano should be active in geologically recent time; second, it should be easily accessible (hence a volcano such as Mount Erebus is not included); and third, the whole selection should represent a variety in volcanic types and eruption risk. Although we cannot expect to read about all the world's 600 active volcanoes in this book, a major shortcoming of the book is that there are many well-known, active volcanoes from certain regions of the world that have not been included. I specifically mention the volcanoes in eastern Asia, especially Japan and Indonesia, which are visited by many tourists every year. Even with the author's three criteria, ignoring a whole region of our planet cannot be justified. Should this book see a second edition, this shortcoming needs to be addressed so that the book is truly planetary and more useful.

The appendices at the end of the book give information on the websites and bibliography related to active volcanoes. Overall, this book is helpful for bringing geology into the global tourist industry. The book also offers interesting trivia. For example, I had read Ernest Hemingway's The Snows of Kilimanjaro, but I did not know that this highest mountain in Africa was given by Queen Victoria as a birthday present to her grandson, Kaiser Wilhelm II of Germany!

\section{Dr. Rasoul Sorkhabi}

Energy \& Geoscience Institute

University of Utah

Salt Lake City

Utah 84108

USA

rsorkhabi@egi.utah.edu 